"This is the peer reviewed version of the following article: Krivokapic-Skoko, B. and Collins, J. (2014), Looking for Rural Idyll 'Down Under': International Immigrants in Rural Australia. International Migration. doi: 10.1111/imig.12174.

This article may be used for non-commercial purposes in accordance with Wiley Terms and Conditions for Self-Archiving." 


\title{
Looking for Rural Idyll 'Down Under’: International Immigrants in Rural Australia
}

\begin{abstract}
This paper outlines the empirical findings of the first national longitudinal study of almost 1,000 recent immigrants who decided to move to non-metropolitan Australia. The national survey (2008-2010) identified that new international immigrants tend to move to rural areas because of the natural beauty, lifestyle and community spirit to be found there, as well as the idyllic image of peacefulness and a relaxing environment associated with these areas. Natural attractors, such as rurality and climate, were important features of the places which, according to the survey, were particularly liked. However, there is tension between the imagined Australian rural ideal and reality, with remoteness, isolation and parochialism being the key features in how the countryside may be misrepresented. The retention of new immigrants in rural places is very strongly related to constructed attractors - the availability and quality of infrastructure, as well as recreational, entertainment and cultural activities.
\end{abstract}

\section{INTRODUCTION}

Since the mid 1990s regionalisation in Australian immigration policy has become more apparent as a number of initiatives encouraging new immigrants to settle in non-metropolitan areas have been introduced. These regional immigration policies and schemes have been described by some scholars (Hugo et al. 2006) as "new paradigms in international migration" because they oppose and challenge the predominantly metropolitan settlements of migrants from the 1950s onwards. However, most of the research to date into the history of immigrant communities in Australia, and the economic and social impacts of Australian immigration, has focused on metropolitan areas. Urban sites were also at the focus of the general literature exploring the experience of recent immigrants in Australia. This paper outlines the findings of a comprehensive cross sectional and nationally-based survey of recent immigrants settling in rural and regional Australia (those who arrived in 2003-2008). The objectives of this national survey were to explore the skills and qualifications of the immigrants, their employment and settlement experience and their satisfaction with the services in the communities in which they were living. The study was explicitly designed to answer the question: what would it take to attract and keep new immigrants in small regional townships and rural areas?

The paper starts by reviewing the literature on attraction and retention of new immigrants in regional and rural areas in Australia and also by looking at the Canadian experience, as Canada is considered to be rather successful in promoting the settlement of immigrants in non-metropolitan areas. The paper then outlines the empirical findings of the first national longitudinal study of almost 1,000 new immigrants who decided to move to non-metropolitan Australia. Supplementary qualitative data gathered from the brief, open-ended survey responses are then discussed, around the issues that make rural Australia attractive to new immigrants. The paper finishes by analysing certain dimensions of the immigrants' settlement experiences such as the role of the host community and the importance of the existence of social anchors. 


\section{ATTRACTION AND RETENTION OF IMMIGRANTS IN REGIONAL AND RURAL AREAS: AUSTRALIAN AND CANADIAN LITERATURE}

Studies aimed at unpacking decisions of immigrants to settle in a particular location in Australia (Maher and Stimson 1994) distinguished between so called "natural" and "constructed" attractors. Natural attractors are the features of the physical environment, climate and physiographic factors, such as the beach, unique flora and fauna, or a sense of remoteness from big cities. The constructed attractors can be economic and socio-cultural, and include factors such as housing and employment, and available social structures such as schools. Murphy (1997, as discussed in Khakbaz et al. 2004: 5) identified the following factors which might have an effect on the initial location of new immigrants in Australia: the location of spouse, family and friends, job opportunities, lifestyle/climate, housing, information flows, links and distance from country of origin, and previous visits to particular places in Australia.. According to Maher and Stimson (1994) social networks and social cohesion, including a welcoming environment, are considered to be the key important factors in determining location preferences of immigrants. In addition to these factors, research by Hazebroek et al. (1994) identified access to a place of worship as being important in explaining immigrants' decisions to settle in a particular locality. Finally, ethnic concentration has been found to have a positive and significant impact on the location choice of immigrants (Le 2008).

Wulff and Dharmalingam (2008) argued that the sole focus of immigration policy should not be the attraction of an increasing number of skilled immigrants to rural and regional Australia, but their retention in these areas. They also argued that social connectedness is rather important for long-term stay in a particular place. According to their empirical findings, based on a national survey of immigrants who came under the Regional Sponsored Migration Scheme (RSMS), the following factors were seen as critical for strong social connectedness of immigrants: family context (families with young children), the length of stay in Australia, and the country of origin. The findings suggest that immigrants who were born in the United States, Canada, South Africa and Zimbabwe tend to establish stronger social ties with their host communities, and therefore are less likely to move (ibidem 2008). Similarly, Hugo et al. (2006: 35) point out that the retention of immigrants in regional areas is an even greater challenge than attracting them, and this can only be achieved "if there is effective integration into the local community". Based on a national survey of skilled temporary migrants in Australia, they suggested that some socio-demographic factors, such as occupation, employment, age, marital status, and the country of origin, can explain retention of immigrants in particular communities.

For comparative purposes this paper also looks at Canadian experience in attracting new immigrants to non-metropolitan areas. In reviewing one of Canada's most successful regional migration programs - the Manitoba Provincial Nominee program (MPNP) - Carter et al. (2008) strongly argued that policy developed locally, and combined with more authority for local administration, leads to "a better outcome" where regional immigration schemes are concerned. In the decade 1991-2001 the retention rate of immigrants in the province of Manitoba was close to 80 per cent (Carter et al. 2008). As the key to success of the MPNP they identified the involvement of communities in settlement planning, more involvement by local employers, and the greater control the province had over the nomination and selection of immigrants. It may be said that community initiatives and partnerships are unique to the MPNP, and under that program communities have signed agreements to support the 
settlement of a given number of immigrants to Manitoba, which include the provision of jobs for immigrants with particular skills.

Canadian academic literature has also documented that immigrants are usually first attracted to rural regions through family and friends, and that the strength of these ties correlates with the likelihood that immigrants will remain in a particular area. Case studies of small communities in Nova Scotia (Flint 2007) and British Columbia (Walton-Roberts 2004) also indicate that immigrants are attracted to regional areas because of the employment opportunities, as well as the "rurality", in terms of open space, safe and healthy environment, and a strong sense of community. Most of the survey participants included in a study of Edmonton, Alberta (Derwing et al. 2005: 16), indicated that quality of life factors, such as good climate and a welcoming social environment, were the best things about living in that particular place. Interestingly, while almost one third of survey participants mentioned the presence of family and friends as the main "pull" factor for moving to Edmonton, "almost, no one (only 2.0\%) mentioned the family and friends as the best thing about living in their city" (Derwing et al. 2005: 16).

According to Canadian sources (Walton-Roberts 2004; Flint 2007; Abu-Ayyash and Broshu 2006; Clutterbuck and Novick 2003; Khan 2006) the local communities are crucial in providing resources and welcoming environment for immigrants. Regarding the successful settlement of immigrants, it is believed that the role of local government is crucial in trying "to build consensus among all residents with respect to community issues such as planning and development" (Flint 2007: 9). Or, as was recognised by the Colchester Regional Development Agency (Nova Scotia), communities have to attract, welcome and embrace immigrants, and become what some Canadian agencies, such as the Federation of Canadian Municipalities, referred to as "Inclusive Communities" (Clutterbuck and Novick 2003). Improving communities' competitive advantage in attracting immigrants has also been on the agenda for Citizenship and Immigration Canada (CIC), which released "A Tool Box of Ideas for Smaller Centres” (National Working Group on Small Centre Strategies 2005). Some of the ideas included in that document are: encouraging intercultural harmony, educating the local population about cultural diversity and antiracism, and including the local Indigenous communities in promoting non-metropolitan areas as a preferable destination for new immigrants. These programmes were very successfully put forward by the communities of Sudbury, Ontario (Block 2006), Sherbrooke, Quebec (Corriveau and La Rougery 2006) and Windsor, Ontario (Munro 2006).

The review of both the Australian and Canadian literature on the factors for attraction and retention of immigrants pointed to employment opportunities as being essential for immigrants' decisions to move into a particular community. What would appear from unpacking immigrants' decisions is that, while family linkages are important for attracting new immigrants (in terms of being information sources and "pull" factors), the quality of life, job and education opportunities play a much larger part in retaining them.

\section{MOVING TO “THE BUSH”: NATIONAL SURVEY OF NEW IMMIGRANTS IN REGIONAL AND RURAL AUSTRALIA}

The empirical data discussed in this paper are based on the survey of recent immigrants living in non-metropolitan Australia.. The survey was part of the project: New Immigrants in the Regional and Rural Australia: Attraction and Retention, funded by Rural Industries Research 
and Development Corporation (HCC06-27). The self- administrated questionnaires were sent to the sample of 2748 immigrants living in rural and regional Australia. The contact details such as the names and addresses were randomly selected from the Department of Immigration and Citizenship (DIAC) Settlement Data Base. The survey was conducted between April and June 2008. The final survey included a total of 915 immigrants living in rural and regional Australia. The overall response rate to this mail survey was close to $30 \%$ per cent. Twenty per cent of the questionnaires were returned mainly because the potential respondents left the address which was listed in the DIAC settlement data base. Such a relative higher rate of RTSs can be explained by a higher mobility of the immigrants during the early stage of their settlements. Most of the respondents (86.0\%) are from New South Wales, Victoria, Queensland, and Western Australia. The profile of the survey, the structure and content of the questionnaire and administration of the initial mail survey, have been explained in more detail in Collins and Krivokapic-Skoko (2009).

The participants were surveyed at three separate stages after their arrival in Australia, in 2008, 2009 and 2010, allowing the longitudinal survey to compile a dynamic picture of the experiences of the newly arrived immigrants. The self-administered questionnaire included closed-ended and Likert-scale responses as well as space for open-ended comments. It consisted of 47 questions which were divided into five main sections: (a) migrant decisions and mobility; (b) qualifications; (c) labour market experience; (d) migrant satisfaction, and (e) community participation.

Almost half of the respondents in this survey came from Main English Speaking (MES) countries; one in four of the respondents came from the United Kingdom and Ireland. The proportion of immigrants from China and India, settling in non-metropolitan areas of Australia, was rather low (5.3\%), while immigrants from the Philippines and from South Africa/Zimbabwe were relatively more represented (10.7\% of the respondents). Around 30 per cent of the respondents in this survey came from non-metropolitan areas in their former country of residence (population of less than 100000 people) while almost 40 per cent came from the communities with less than 200000 inhabitants. Following Hugo (2005) and Gray at al. (1991: 1) the term non-metropolitan is used to refer to the parts of the country outside of centres with no more than 100000 inhabitants. Hugo et al (2006: 27) adopted a different approach defining non-metropolitan areas as communities with less than 200000 inhabitants. Around $10 \%$ of the participants in this survey came from rural towns with up to 10000 people. Interestingly, there was a large number of immigrants from the United Kingdom and Ireland who used to live in small rural towns before immigrating to Australia.

Regarding the visa category, only one third of the respondents (31.2\%) came under one of the specially designated migration schemes, Regional Sponsored Migration Scheme, SkilledDesignated Area Sponsored and Skilled Independent Regional Scheme. Most of the immigrants included in this survey (63.5\%) came under the category of 'other' such as the family reunions or the general skilled stream.

Immigrants living in regional and rural Australia are highly qualified and endowed with significant human capital. According to this national survey of new immigrants, almost 95 per cent of the respondents had at least a high school certificate, 45 per cent held a university degree, while one in five respondents held a postgraduate degree. More than half of the immigrants were involved in the fields of health, engineering, business and education before moving to Australia. One in 10 of the survey participants had studied in the field of technology or science (mathematics, natural and psychical sciences). Clearly, immigrants 
living in regional and rural Australia are highly skilled, and potentially could address a severe shortage of professionals (health and education professionals in particular).

According to the results of the survey, immigrants settling in rural and regional areas tended to immigrate to Australia in the first place mainly due to non-economic reasons. Around 70 per cent of the respondents decided to move to Australia to join family/relatives or because of marriage or for a better future for their families. Apparently, the immigrants from the MES countries are more likely to come because of Australian features, such as life style or climate. Respondents who came under one of the specially designated migration schemes also indicated 'the better future for their family' as the main reason for immigrating - it accounts for more than 35 per cent of the answers to this question. Work and business opportunities account for less than 10 per cent of the reasons mentioned by the survey respondents in general.

However, once in Australia, migrants' decisions about moving to a particular place are significantly shaped by job opportunities. More than 40 per cent of the respondents living in regional and rural Australia listed job opportunities as the main reason for living in their current place of residence. At the same time, the results of this survey also showed that the most recent immigrants settling in non-metropolitan Australia were strongly attracted to regional areas because of natural attractors, such as the lifestyle, the climate, affordability of living and the friendly environment, and taken together this was the most common reason given by the respondents. These findings strongly correspond with the results of Canadian studies (Derwing et al. 2005; Derwing and Krahn 2008, Flint 2007, Walton-Roberts 2004) which showed that the other key element in the decision making process of immigrants are the life style factors ( Figure 1).

\section{Insert Figure 1 here}

The results of the longitudinal survey indicate that immigrants moving to non-metropolitan Australia tended to remain in the area in which they first settled. By Stage 3 of the longitudinal survey more than 92 per cent of the participants were still living in the same rural town and generally they were very satisfied with the current place, since more than 80 per cent of them would encourage relatives or friends to move there.

The survey showed that the immigrants in non-metropolitan areas had a positive labour market experience. Firstly, they had a high rate of economic participation; only seven per cent of the survey participants were unemployed at the time the survey was carried out. The unemployed immigrants tended to come from non-English-speaking countries, mainly the Philippines and China. Almost 57 per cent of the participants in this national survey were wage or salary earners, and one in 10 was conducting their own business. Secondly, international immigrants living in non-metropolitan Australia did not wait long for their first job. In the case of almost half of the respondents it took only up to a month to find their first job, and one in five found their first job within two weeks. Thirdly, almost one third of the respondents did not experience any problems finding work. However, 70 per cent of the immigrants coming from the non-MES countries experienced some problems in finding a job. The immigrants across the board who experienced some problems mentioned a lack of recognition of overseas qualifications, a lack of local experience and language difficulties as major difficulties in finding a job. Again, these problems tended to be mainly reported by the immigrants from the non-MES countries. Finally, data show favourable outcomes in terms of 
the immigrants' economic wellbeing, since one third of the respondents owned a home and the "owner-mortgage" category accounted for more than half of the housing arrangements.

Furthermore, this longitudinal survey shows that the immigrants who were employed at the time of conducting the national survey in 2008 were likely to still be employed three years later, and almost 80 per cent of these were working in the same jobs. Only five per cent of the respondents were unemployed and looking for work. An increasing number of immigrants established their own business enterprise and by Stage 3 almost one in five respondents was self-employed. Most respondents who were conducting their own businesses in Stage 1 of the longitudinal survey were still conducting their own businesses in Stage 3, indicating that most immigrant business enterprises are successful.

There is some initial evidence of improved employability of immigrants in Australia. With time spent in Australia, there is attrition in the number of respondents who had difficulties due to lack of experience in the Australian labour market and in using the English language. In Stage 1 (2008) one in ten respondents indicated that the main problem for them in finding jobs was insufficient local experience and a lack of English language skills; only one third did not experience any problems in finding employment. Three years later, in Stage 3 of the longitudinal survey, half of the respondents did not experience any problems in finding a new job, and insufficient local experience and a lack of English language skills now each accounted for around only five per cent of the problems encountered.

This emerging occupational upward mobility may be partly explained by the fact that many recent immigrants were taking further education in Australia. Thirty five per cent of the respondents included in this longitudinal survey received further qualifications after moving to Australia. A significant proportion of the respondents (45\%) obtained different trade qualifications, which expectedly improved their employability in the labour market or helped them remain and get promoted at their current job. According to this longitudinal survey, by Stage 3 one in five immigrants living and working in regional areas received a postgraduate degree after moving to Australia. Very importantly, half of the participants in this survey still intended to undertake further study or training at a university or other education institution. These findings of clear intentions of immigrants to acquire new skills and obtain additional formal qualifications should be welcomed by policy makers and addressed by regional education providers.

\section{LIVING IN “THE BUSH”: RURAL IDYLL AND REALITY}

Lifestyle considerations (friendliness of the people, rurality, environment, relaxed atmosphere, and climate) were the main things that immigrants liked about the place in which they were living. Almost one third of the respondents emphasized friendliness of the people and/or the sense of community as the things they liked most about living in their current city or town (Table 1).

\section{Insert Table 1 here}

When it comes to what rural immigrants disliked about the place in which they were currently living, the categories of responses were very similar to the ones used for outlining the things most liked about the city or town. Inadequate amenities (this category also includes poor infrastructure) was the most common dislike amongst respondents (see Table 1). Particularly 
common complaints were about poor retail facilities, poor selection of goods and services, inadequate public transport, poor roads and footpaths, and a limited range of recreational, entertainment or cultural activities. Climate was the next most common complaint (one in six respondents disliked the weather), with the weather usually too hot, too cold, too windy and/or too cyclonic. Rurality appeared as the next most common dislike, with the distance to larger centres and international airports being of a particular concern. Other respondents found their work opportunities limited, animals and pests annoying (particularly flies) and the fact that they were too far away from their families (many of whom lived overseas). However, the absence of family and friends was only sporadically mentioned as the biggest problem of living outside metropolitan areas (less than five per cent of the answers), aligning with the results of Canadian studies (Derwing et al. 2005; Derwing and Krahn 2008) which emphasised that only two per cent of respondents mentioned family and friends as the best thing about living in their current place of residence.

New immigrants living in rural and regional Australia are likely to take part in activities organised by local communities and in activities involving sport or different hobbies. There is an apparent difference in types of community activities attended by immigrants from the Main English Speaking (MES) countries and those from the non-MES countries. Immigrants from the non-MES countries were mainly involved in religious activities and voluntary ethnic associations. In contrast, immigrants from the MES countries tended to be mainly involved in sport activities and general activities organised by the local community. Seventy per cent of the respondents taking part in religious activities were from the non-MES countries. One in three immigrants from the non-MES countries was involved in church and religious activity within a community. The immigrants from the Philippines were more likely than others to attend church or religious activities. Immigrants from the Philippines and South Africa/Zimbabwe tended to have stronger ethnic group involvement. Almost half of the immigrants from the Philippines and South Africa/Zimbabwe had some contact with ethnic voluntary associations, compared with less than 10 per cent of immigrants from the United Kingdom and Ireland. Finally, based on the findings of this survey, it may be said that there is a relatively high level of interaction between rural immigrants and their neighbours. Eighty seven per cent of the respondents had visited their neighbours since moving to their current place of residence.

The survey also explored the level of the immigrants' satisfaction with the help and information received from DIAC, local city councils and Information \& Neighbouring Centres. Most of the immigrants used the services provided by DIAC and 65 per cent of them were satisfied with the information and help provided. Half of the respondents did not use any services provided by Information \& Neighbouring Centres while one third did not use any services provided by the local city councils. However, immigrants who did use these services tend to be reasonably satisfied with the information and help they received.

The participants in this survey strongly indicated that they were made welcome since moving to their current place of residence. In all three stages of the longitudinal survey over 90 per cent of respondents felt welcome or somewhat welcome. The empirical results indicated that with time new immigrants tended to participate more actively in community activities. The most common activities regularly attended by respondents were those arranged by the local community and those involving sports or hobbies. By Stage 3 of the longitudinal survey 55 per cent of the respondents in this survey had developed strong connections with the community, as considered using the criteria developed in literature on social connectedness (Wulff and Dharmalingam 2008). The findings of the empirical research also show that 
networks established by immigrants in rural communities do not centre exclusively around people coming from the same country, as only around 15 per cent of the respondents had mainly compatriots living locally as their friends. All these results indicate that with time new immigrants tend to establish stronger ties with their communities, which would indicate effective integration into the local community and their intention to settle for a longer period.

However, personal experience of racial discrimination or abuse while living in rural and regional communities was revealed by one in five respondents and this is of some concern. According to this survey, family members and friends of the respondents experienced almost the same occurrence of racial discrimination or abuse. Although it may be difficult to compare these results with the other studies (mainly because of the different scales), research by Forrest and Dunn (2013, p. 8) on the experience of racism in rural South Australia suggests that "there were noticeably lower levels of experiences of racist behaviour by ethnic minority groups members than the analysis of attitudes might have suggested”.

Respondents in this survey were also able to freely express their views about any issue in relation to their settlement experience. They were asked to write this down in a space provided at the end of the questionnaire. According to Niedomysl and Malmberg (2009) open-ended questions are particularly useful in researching immigrants' motives, because responses are given spontaneously and it is possible to avoid bias that may result from suggesting responses to the immigrants included in the survey. The responses varied from a few phrases to a couple of paragraphs, or what Jackson and Trochim (2002: 308) refer to as "a free list in the context" type of text. The response rate to this section of the national survey was 34.6 per cent, as 333 respondents decided to provide additional comments about their attitudes to the whole process of settling in rural Australia. The analysis of the textual data collected in the open-ended survey was based on the words as units of analysis or key words in context (Jackson and Trochim 2002).

Integration of the themes on the living experience of international immigrants, gathered from the open-ended responses, is presented in Figure 2. Categories used to analyse the data were inductively developed, and three main groups of the themes were mapped: (a) community, (b) landscape and (c) employment related themes. Following Miles and Huberman (1994) we used a comment (a clause or section containing a single attitude/position/stance) as a starting point, with themes considered as a compilation of comments. In analysing key words and comments, provided in the open-ended responses, it soon became apparent that the same categories tended to appear in both positive and negative comments about living in a particular community.

General positive comments about moving to Australia were associated with the beauty and attractiveness of the place. Generally this is what Holliday and Coombest (1995) would refer to as anti-urban sentiment and pro-rural movement, with an emphasis on the search for a better environment or tranquil lifestyle. Within this theme rural areas are perceived as rural idyll - picturesque scenes without pollution and traffic. Recent immigrants are attracted to a place because of its natural beauty, community spirit and idyllic image of peacefulness and a relaxing environment. Rural aspects of life, friendliness of the people, and environmental factors were recognised by the immigrants coming from a variety of countries. Lifestyle considerations (friendliness of the people, rurality, environment, relaxed atmosphere, and climate) were the main things immigrants liked about the place in which they were living. 
However, what makes the findings of the open-ended responses notable is a very strong polarisation in the perception of rural communities in Australia. It seems that these perceptions are evident in extremely positive or extremely negative comments. The ambivalent nature of responses to rurality in the Australian context is put nicely by an immigrant from Thailand: "I like where I live due to being peaceful and friendly people ... but due to our area being far from main town in shire ... seems like we appear to be forgotten when it comes to basic services like roads, water, electric, like we got to last without”. Many immigrants already living in rural areas would agree that the place itself is attractive, but isolation and lack of desired career opportunity would make them consider re-locating.

For some immigrants rural communities are very parochial and this clearly would make the settlement process more difficult. They found rural communities to be very "cliquey" and close knit. "They have all grown up together and have lived here all their lives. They are very reluctant to allow strangers in", or as another ethnographic account shows: "People do not accept outsiders into local community easily". The immigrants also called for government support for rural and regional Australia as: "I only wish that the government can help us here ... to put more on jobs so that this place won't turn out to be a ghost town. This is a good and quiet place to live. The only reason why people leave this place is because of the lack of jobs" (immigrant from the Philippines). Some immigrants also provided somewhat depressing accounts of life in regional Australia, like: "About 25 per cent of the town's population have been here for more than ten years. Several of these prominent locals tell me they are leaving soon. It's unsettling for some (arriving from a community that is much more fixed/stable) to live in a transient town” (immigrant from the United Kingdom).

The themes generated by the open-ended responses strongly reinforced findings from the quantitative surveys, that employment and local employers are becoming central for happiness, satisfaction, and well being of immigrants and their families, as well as for their integration into a community. New international immigrants living in regional Australia complained about public transport, infrastructure, the retail sector, as well as recreational, educational, entertainment or cultural activities. The themes related to attraction and retention of immigrants in regional Australia are nicely summarised in the words of one the respondents in the national survey: "Our town is very multicultural and welcoming of immigrants due to skills shortage. It's a good place to live and we are happy with decision to live here. However, it is expensive and remote. Services are limited. It is expensive to travel to obtain service” (immigrant from South Africa).

Immigrants also tended to settle in a particular community because of strong ethnic social networks, availability of cultural support and religious activities, as well as the existence of "meeting" places. Presence of large immigration communities, ethnic networks, or clubs has been already identified as significant in attracting new immigrants (Hazebroek et al., 1994; Le 2008 Akbari, 2008). The construction or acquisition of shared community spaces, so that immigrant groups could "meet at certain places of a common interest", can be seen as part of immigrant adaptation to a new Australian landscape and the desire for staying in a new place. For immigrants in general, a place of worship, a club, or a cultural centre can therefore become a "social anchor" in their new environment, providing identification and belonging as well as a sense of identity. So, ethnic sites or buildings can become essential reference points in ethnic identity because of special cultural, social and spiritual associations with the place. 
These sites can also significantly impact the dynamics of social cohesion and intercultural relations within communities, particularly if they are built through "cross-cultural design and planning practices” (Stewart et al., 2003: 240).

Apart from diversity, a culturally rich environment has great appeal to immigrants and therefore can become a "selling point" in attracting new immigrants to rural towns. Rural cultural research suggests that the arts in regional and remote communities provide an inclusive base from which communities can develop tolerance and understanding (Dunphy 2009). Strengthening community capacity and the building of relationships creates a strong sense of place and can lead to increased retention of skilled and educated immigrants.

\section{CONCLUDING COMMENTS}

New international immigrants moving to non-metropolitan Australia are highly qualified, bring significant human capital and show a high economic participation. Apart from job opportunities they tend to be attracted to rural places because of their natural beauty, community spirit and idyllic image of peacefulness and a relaxing environment. Positive comments about moving to regional and rural Australia are usually associated with the beauty and attractiveness of the place, and "quality of place" has clearly become a significant factor in the location choice for new international immigrants.

Rural Australia, or what is fondly termed "the Bush", offers unique landscape (Tonts and Grieve 2002). International immigrants moving to "the Bush" singled out friendliness of the people, beauty and attractiveness of the natural landscape, the peaceful and safe environment without pollution and traffic, and warm climate as the main features they liked about the place in which they were living. Sense of community, mateship and cohesion are generally seen (Dempsey 1992) as part of the unique Australian rural ideal. However, as rural places also tend to be homogenous, inward looking, and hesitant to "outsiders", these features of rural idyll can easily turn into big challenges for immigrant groups from different cultural and language backgrounds. The respondents in this survey singled out conservatism and parochialism as the downside of living in rural communities. Further tension between the imagined Australian rural ideal and reality is related to the landscape itself, with remoteness and isolation being the key features in how the countryside may be misrepresented. Considering the rather positive labour market experiences and economic well being of immigrants it may be that perceptions and realities of the Australian life style are silently bargained (Torres, Popke and Hapke 2006) in the context of individual migrant experience.

However, the single most important factor about which regional and rural immigrants complain is inadequate local services and facilities. Thus, the immigrants' settlement experience is very strongly related to constructed attractors - the availability and quality of public transport, infrastructure, and the retail sector, as well as recreational, entertainment or cultural activities. These are areas where there may be more scope for policy intervention, such as particular infrastructure investments, in order to ease the urban-rural divide in accessing services.

The challenges faced by regional and rural communities in attracting new, globally mobile, skilled immigrants (Derwing and Krahn 2008), place rural and regional communities across developed nations such as Australia, Canada and New Zealand in a position of having to 
compete for these skilled immigrants, including the younger generation of skilled immigrants (generation $\mathrm{X}$ and $\mathrm{Y}$ ). Improving communities' competitive advantage in attracting these categories of immigrants is an emerging issue, which can be addressed using the concept of creative communities (Florida 2002). Thus, communities with a high level of human capital, as well as vibrant and diverse arts and cultural life, sport and outdoor activities, and educational opportunities, and, furthermore, which can embrace creative thinking and tolerance, are the communities most likely to attract new immigrants. 


\section{REFERENCES}

Abu-Ayyash, C. and Brochu, P.

2006 "The uniqueness of the immigrant experience across Canada: A closer look at the region of Waterloo", Our Diverse Cites, 2: 20-27.

Block, T.

2006 "Approaches to attracting and retaining newcomers in the City of Greater Sudbury, Ontario”, Our Diverse Cities, 2: 36-44.

Carter, T, Morrish, M, and Amoyaw, B.

2008 "Attracting immigrants to smaller urban and rural communities: Lessons learned from the Manitoba provincial nominee program”, Journal of International Migration and Integration, 9: 161-183.

Clutterbuck, P. and Novick, M.

2003 Building Inclusive Communities: Cross-Canada Perspectives and Strategies, Federation of Canadian Municipalities and Laidlaw Foundation, Ottawa and Toronto, ON.

Collins, J. and Krivokapic-Skoko, B.

2009 Attraction and Retention of New Immigrants in Regional and Rural Australia: Literature Review and National Survey 2008. Rural Industries Research and Development Corporation, Canberra

Corriveau, A-M. and La Rougery, J-Y.

2006 "Welcoming and integrating immigrants: Sherbrooke's experience", Our Diverse Cities, 2: 102-106.

Dempsey, K.

1992 "Mateship in country towns. In Carroll, E. (ed) Intruders in the Bush: The Australian Quest for Identity. Oxford University Press, Melbourne, $2^{\text {nd }}$ ed., 131-142

Derwing, TM, Krahn, H, Foote, J. and Diepenbroek, L.

2005 The Attraction and Retention of Immigrants to Edmonton, Prairie Centre of Excellence for Research on Immigration \& Integration, The University of Alberta, Edmonton, Canada.

Derwing, T.M. and Krahn, $\mathrm{H}$.

2008 "Attracting and retaining migrants outside the metropolis: Is the pie too small for everyone to have a piece? The case of Edmonton, Alberta”, Journal of International Migration and Integration, 9: 185-202.

Dunphy, K.

2009 Developing and Revitalizing Rural Communities Through Arts and Creativity, The Creative City Network of Canada, March 2009 
Flint, J.D.

2007 Rural Immigrants Who Came to Stay: A Case Study of Recent Immigrants to Colchester County, Nova Scotia, Atlantic Metropolis Centre, Working Paper No. 072007, Halifax, NS, Canada.

Florida, R.

2002 The Rise of the Creative Class: And How It's Transforming Work, Leisure, Community and Everyday Life, Basic Books, New York.

Forrest, J. and Dunn, K.

2013 "Cultural diversity, racialisation and the experiencee of racism in rural Australia: the South Australian case”, Journal of Rural Studies, 30, pp. 1-9.

Gray, I. W., Dunn, P. F., Kelly, B.M. , and Williams, C. J.

1991 Immigrant Settlement in Country Areas. Bureau of Immigration Research, Australian Government Publishing Service, Canberra, ACT.

Hazebroek, A, Steward, K, Gaston, G, Holton, R. and Tai Tan, Z.

1994 Planning Criteria for the Provision of Immigrant Services in New Areas, Bureau of Immigration Research, Australian Government Publishing Service, Canberra, ACT.

Holliday, J. and Coombest, M.

1995 "In search for counterurbanisation: Some evidence from Devon on the relationship between patterns of migration and motivation”, Journal of Rural Studies, 11(4): 433446.

Hugo, G.

2005 'The state of rural population'. In C Coklin \& J Dibden (eds) Sustainability and Change in Rural Australia, UNSW Press, Sydney, pp. 56-79.

Hugo, G, Khoo, S-E. and McDonald, P.

2006 “Attracting skilled migrants to regional areas: What does it take?”, People and Place, 14 (3): 26-36.

Jackson, K. and Trochim, W. M.

2002 "Concept mapping as an alternative approach for the analysis of open-ended survey responses”, Organisational Research Methods, 5(4): 307-336.

Khakbaz, M, Gopalkrishnan, N. and Babacan, H.

2004 "Sustaining the regions: Issues of international migration, settlement and ethnic diversity”, paper presented to the $12^{\text {th }}$ Biennial Conference: Population and Society: Issues, Research, Policy, Canberra, 15-17 September 2004.

Khan, C.

2006 “"The blind spot': Racism and discrimination in workplace”, Our Diverse Cities, 2: 61-66.

Le, A.T. 
2008 “'Location, location, location: Where do immigrants reside in Australia”, Journal of International Migration and Integration, 9: 345-365.

Maher, C. and Stimson, R.J.

1994 Regional Population Growth in Australia: Nature, Impacts and Implications, Australian Government Publishing Service, Canberra, ACT.

Miles, M. and Huberman, A. M.

1994 Qualitative Data Analysis (2nd ed), Sage, Thousand Oaks, CA

Munro, M.

2006 "Being accountable on the big stage: Joining the Canadian coalition of municipalities against racism and discrimination”, Our Diverse Cities, 2: 83-88.

National Working Group on Small Centre Strategies

2005 Attracting and Retaining Immigrants: A Tool Box of Ideas for Smaller Centres, Citizenship and Immigration Canada, Victoria, BC.

Niedomys, T. and Malmberg, B.

2009 "Do open-ended survey questions on migration motives create coder variability problems?”, Population, Space and Place, 15: 79-87.

Stewart, S., Hanna, B., Thompson, S., Gusheh, M., Armstrong, H. and van der Plaat, D.

2003 "Navigating the sea of diversity: Multicultural place-making in Sydney", International Journal of Diversity in Organisations, Communities and Nations, 3: 239-252

Tonts, M. and Grieve, S.

2002 "Commodification and creative destruction in the Australian rural landscape: The case of Bridgetown, Western Australia, Australian Geographical Studies, 40(1):58-70

Torres, R.M., Popke, J.E. and Hapke, H.M.

2006 "The South's silent bargain: Rural restricting, Latino labour and the ambiguities of migrant experience". In Smith, H. A. and Furuseth, O.J. (eds) Latinos in the New South: Transformations of Place. Burlington, VT: Ashgate, 37-67

Walton-Roberts, $\mathrm{M}$.

2004 Regional Immigration and Dispersal: Lessons from Small- and Medium-sized Urban Centres in British Columbia, Vancouver Centre of Excellence, Working Paper No. 04-03, Burnaby, BC, Canada.

Withers, G. And and Powall, M.

2003 Immigration and the Regions: Taking Regional Australia Seriously. The Chiefly Research Centre: Sydney

Wulff, M. and Dharmalingam, A.

2008 "Retaining skilled migrants in regional Australia: The role of social connectedness", Journal of International Migration and Integration, 9: 147-160. 
Figure 1

Reasons for moving to the rural and regional places

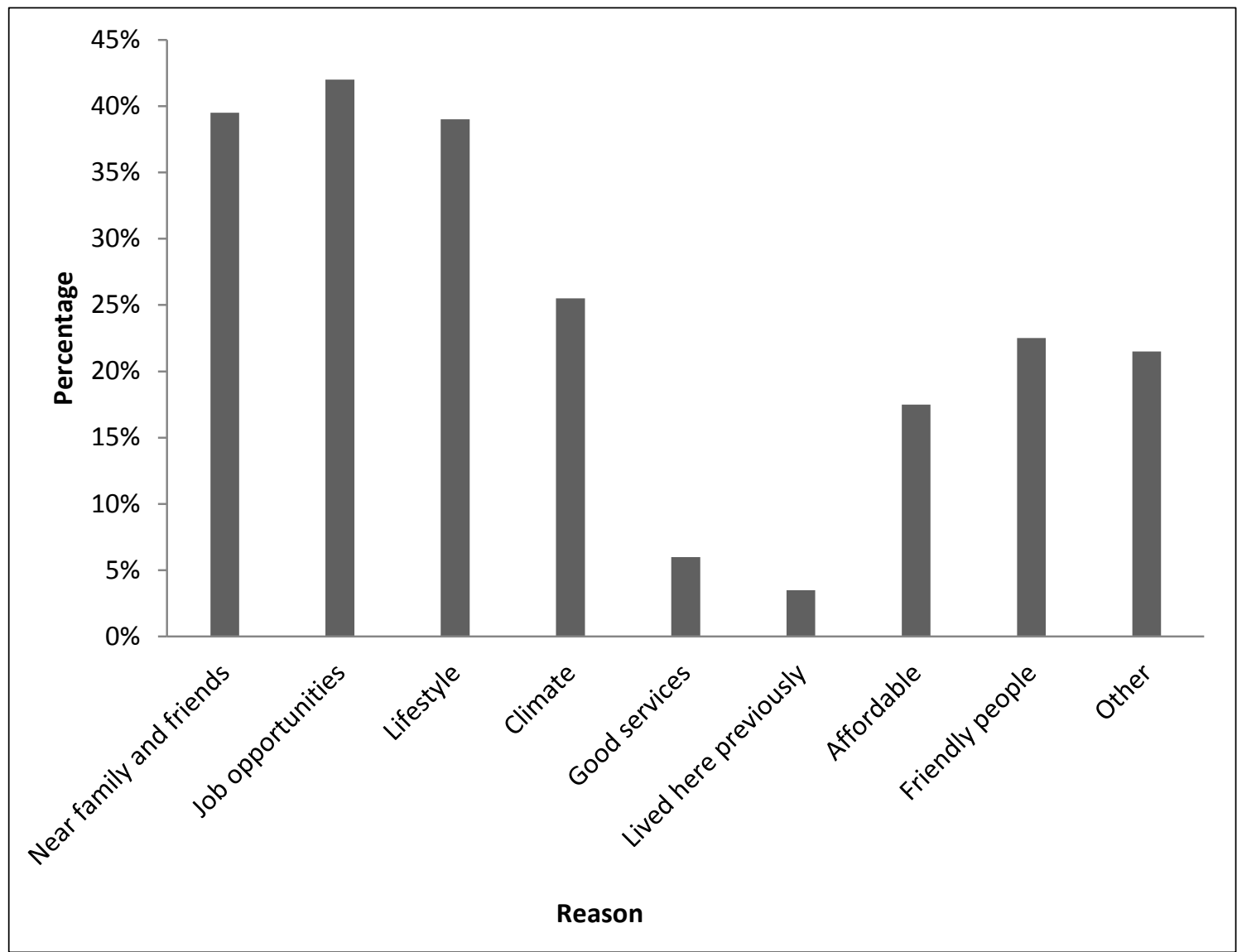

Source: Survey of new immigrants in regional and rural Australia, N=915. 
Table 1

Features of the rural and regional places most liked and disliked

\begin{tabular}{|lclc|}
\hline \multicolumn{2}{|c|}{ Like/positive aspects } & \multicolumn{2}{c|}{ Dislike/negative aspects } \\
& \% stating & Features & \% stating \\
Features & & & \\
Friendly people & 29.0 & Amenities & 61.0 \\
Rurality & 22.0 & Climate & 15.0 \\
Lifestyle & 19.0 & Lack of job opportunities & 13.0 \\
Landscape & 18.0 & Rurality & 12.5 \\
Climate & 15.5 & Current job & 6.0 \\
Amenities & 12.5 & Animals/pests & 6.0 \\
Work & 7.0 & Not being close to family & 5.0 \\
Being close to family & 4.5 & Environment & 2.5 \\
Safety & 4.5 & Lack of education opportunities & 2.5 \\
Education opportunities & 3.0 & Safety & 1.0 \\
Affordability & 2.5 & Landscape & 1.0 \\
& & & \\
\hline
\end{tabular}

Source: Survey of new immigrants in regional and rural Australia, N=915. 
Figure 2

Positive and negative aspects of living in rural and regional Australia
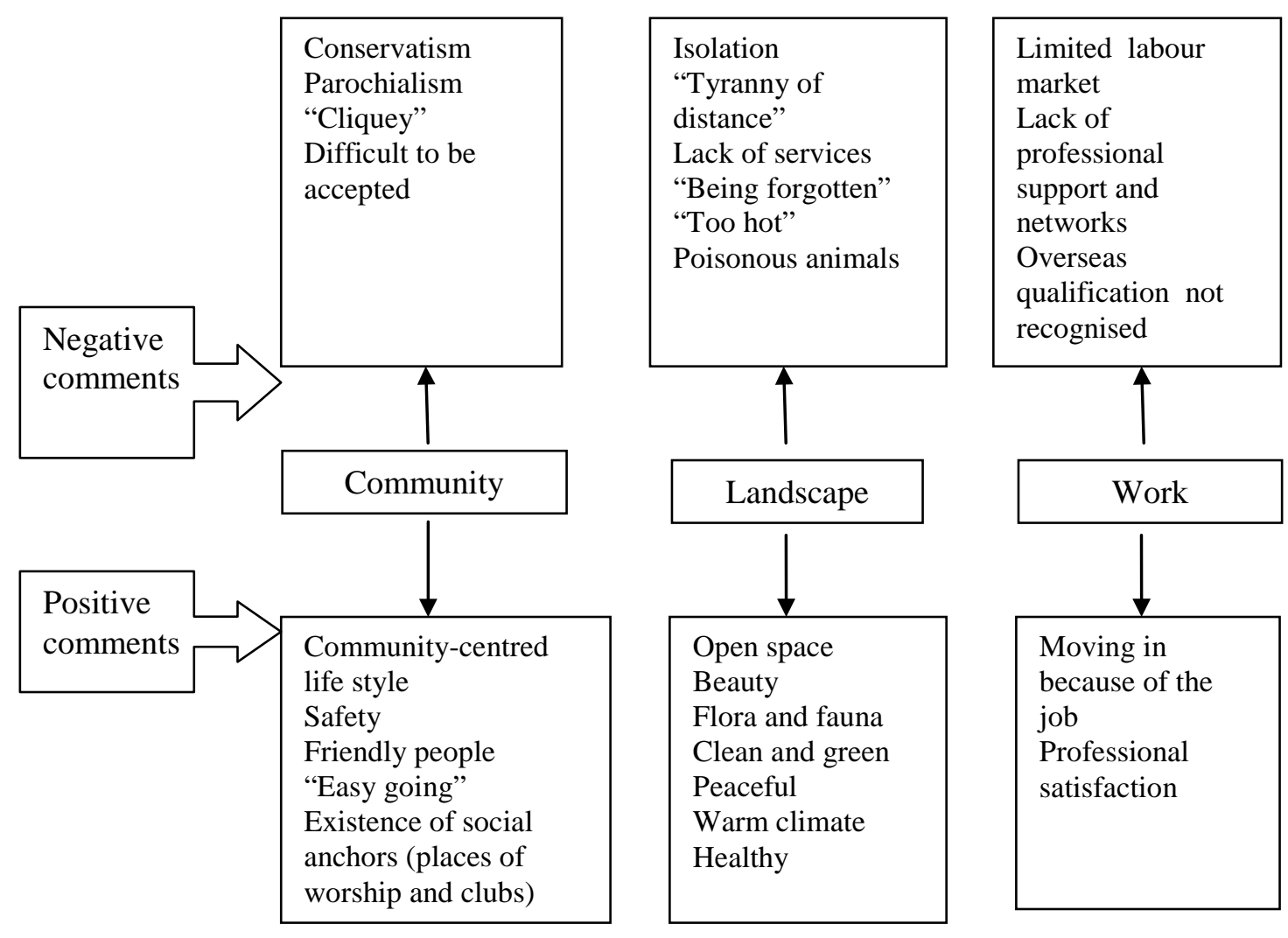

Source: Survey of new immigrants in regional and rural Australia (open-ended responses). 
